\title{
Rapid automated selection of mammalian cell line secreting high level of humanized monoclonal antibody using Clone Pix FL system and the correlation between exterior median intensity and antibody productivity
}

\author{
Suba Dharshanan ${ }^{1,2} \square \cdot$ Heilly Chong $^{1} \cdot$ Cheah Swee Hung $^{2} \cdot$ Zulkeflie Zamrod $^{3} \cdot$ Nazlee Kamal $^{3}$ \\ 1 Protein Science Department, Inno Biologics, Nilai, Negeri Sembilan Malaysia \\ 2 Department of Physiology, Faculty of Medicine, University of Malaya, Kuala Lumpur Malaysia \\ 3 Inno Bio Ventures, Damansara, Kuala Lumpur, Malaysia
}

$\triangle$ Corresponding author: suba.dharshanan@innobiologics.com

Received October 23, 2010 / Accepted January 14, 2011

Published online: March 15, 2011

(C) 2011 by Pontificia Universidad Católica de Valparaíso, Chile

\begin{abstract}
The selection of high-producing mammalian cell lines is a crucial step in process development for the production of biopharmaceuticals. Previously, cloning by limiting dilution method was used to isolate monoclonal NSO cells secreting high levels of humanized-C2 monoclonal antibodies. However limiting dilution method is time consuming, has low probability of monoclonality and is significantly limited by the number of clones that can be feasibly screened. In order to minimize the duration and to increase the probability of obtaining high-producing clones with high monoclonality, an automated colony picker, Clone Pix FL system was used to replace limiting dilution method. We were able to screen $1 \times 10^{5}$ clones secreting humanized monoclonal antibodies and high producer clones were selected in just 7 days. Briefly, semi-solid media was used to immobilize single cells separately and allow them to proliferate into discrete clones. The high viscosity nature of the semi-solid media retains the secreted products in the vicinity of the associated clones. Using Clone Pix FL system, all clones were screened and the producer clones with different exterior fluorescent intensities were automatically isolated. We were able to isolate rare high-producers (> $3000 \mathrm{FU})$ with frequency of as low as $0.003 \%$ of the population. A quantitative ELISA was also performed to evaluate the correlation between the fluorescence intensity of clones with its corresponding antibody productivity. Clones with fluorescence intensity of $<1000 \mathrm{FU}$ showed relatively low antibody productivity compared with those greater than $1000 \mathrm{FU}$; however above this there was no correlation of production with the increase in fluorescence intensity. Hence, although the high-throughput, rapid and automated nature of Clone Pix FL system allows the screening of large number of cells in a short period of time with also an increased in the probability of obtaining rare and precious high-producing clones, downstream analysis are still vital to determine the 'actual' and stable high producer clones.
\end{abstract}

Keywords: cancer immunotherapy, high producer cell line, high-throughput selection, NS0 cells, semisolid media

\section{INTRODUCTION}

Production of complex recombinant proteins often requires the use of mammalian cells, which is an expensive process with often disappointingly low yields and long development times (Wurm, 2004; Butler, 2005). Due to the growing demand for therapeutic proteins especially monoclonal antibodies, generation of high producing clones is a perquisite for achieving antibody yields suitable for biopharmaceutical production (Carroll and Al-Rubeai, 2005). However, in many industrially important cell lines used to produce recombinant proteins such as Chinese hamster ovary (CHO), mouse myeloma line (NSO) and hybridomas, only a minority of clones show productivity significantly above average (Browne and Al-Rubeai, 2007). Thus, in order to have a reasonable probability of finding rare high producing clones, a large number of clones need to be screened. 
Limiting dilution cloning (LDC) is the most commonly used traditional method, owing to its relative simplicity and low cost. In this method, transfected cells are diluted into microtiter plates at an average of less than one cell per well. Antibody producing wells containing clones presumably derived from single cells are selected for further analysis. However, due to the obvious low density, the viability of single cells is very low even in the presence of feeder cell layers. This will increase the risk of losing high producing clones. Besides that, the low throughput nature of this method significantly limits the number of clones that can feasibly be screened. The use of liquid media in this method also makes the selection of monoclonal colonies to be labor intensive and time consuming (Underwood and Bean, 1988). Thus, the chances of obtaining high-producing monoclonal colonies through this method are extremely low.

Fluorescence activated cell sorter (FACS) have been used to screen several million cells and single clones could be isolated in shorter time (Carroll and Al-Rubeai, 2004; Kacmar and Srienc, 2005; DeMaria et al. 2007). Although FACS is higher throughput compared to LDC, FACS is more suited for the selection of high-producers of non-secreted proteins (Meng et al. 2000; Yoshikawa et al. 2001). This is because FACS measures productivity based on cell-surface expression and secreted proteins such as monoclonal antibodies are quickly dissociated from cells when liquid media is used. It was also reported that through a kinetic analysis of hybridoma clones, there is no correlation between the amount of cell surface antibody and the level of antibody in cell culture supernatants, which therefore limits the use of FACS for isolation of secreting clones.

In order to retain secreted recombinant proteins in the vicinity of the secretary clones, semi-solid media has been employed. Semi-solid media which has high viscosity and minimizes diffusion of secreted proteins is used in three popular selection methods, matrix-based selection assay (MBSA) (Frykman and Srienc, 1988), gel microdrop technology (GMT) (Akselband et al. 2003) and laser-enabled analysis and processing (LEAP) (Koller et al. 2004). Using MBSA method, clones with a five-fold superior productivity compared to the highest producing clone selected by LDC method have been isolated (Borth et al. 2000). Furthermore, using MBSA method, it took only 480 subpopulations to identify highproducing clones compared to 4320 subpopulations when done by LDC method. Via GMT method, the isolation of rare high producing mammalian cells with a two- to five-fold increase in specific productivity had also been achieved. Similarly, through LEAP method an increase of five- to twenty-fold in productivity, a significant decrease in the level of heterogeneity within selected lines and higher levels of secreted protein have also been shown (Hanania et al. 2005).

Nevertheless, the disadvantages of MBSA, GMT and LEAP methods have also been reported. The MBSA method is unsuitable for fragile cell types and requires laborious optimization. Likewise, GMT method is described as being user unfriendly, needing extensive optimization of conditions for each cell line used and requiring dedicated equipment. Additionally, due to low density seeding of cells used to ensure single cell occupancy in beads, only $10-15 \%$ of the beads contain single cells, which means up to $90 \%$ of the beads analyzed are empty and wasted. Also, GMT method is reported to reduce the viability of some cell types commonly used for expression of recombinant proteins, most notably NS0 cells (Barnes et al. 2001). Finally the use of laser technology in LEAP method to eliminate unwanted clones may damage high producing clones (Browne and Al-Rubeai, 2007).

Roque-Navarro et al. (2003) had used the limiting dilution method to isolate monoclonal NSO cells secreting high levels of humanized-C2 monoclonal antibodies (hum-C2 mAbs). We have used the method described Roque-Navarro et al. (2003) to humanize murine-C2 mAbs, however, the Clone Pix FL system was employed instead of the limiting dilution method in order to minimize the duration of clone selection and increase the probability of obtaining high-producing clones with high monoclonality. We also evaluated the correlation between exterior fluorescence intensity and antibody productivity using quantitative enzyme-linked immunosorbent assay (ELISA). The hum-C2 mabs were engineered to have lower immunogenicity compared to its precursor which was developed in the mouse through hybridoma technology (Mateo et al. 2000; Yazaki et al. 2004). The hum-C2 mAb is of immunoglobulin isotype $\mathrm{G}$ subclass $1(\lg \mathrm{G} 1)$ isotype and it is highly specific for a colorectal tumor associated antigen (C2), a novel 145-190 kilo dalton (kDa) glycoprotein preferentially expressed on the surface of malignant colorectal cells (Iznaga-Escobar et al. 2004). 


\title{
MATERIALS AND METHODS
}

\author{
Humanization of mouse monoclonal antibodies: plasmid construction and transfection
}

Plasmids coding for humanized heavy and light antibody chains were constructed using methods described by Roque-Navarro et al. (2003) with minor modifications. Total ribonucleic acid (RNA) was extracted from C2-antibody producing murine hybridoma (kindly provided by Cristina Mateo, Centre of Molecular Immunology, Havana, Cuba) using RNeasy mini kit (Qiagen, GmbH, Hilden, Germany). The complementary deoxyribonucleic acid (cDNA) synthesis of the variable region of heavy chain (VH) and light chain (VL) was performed using Superscript III first strand synthesis system (Invitrogen, Life Technologies, Carlsbad, CA, USA) and amplified by PCR using Taq DNA polymerase recombinant (Invitrogen). The PCR products were purified using QIAquick polymerase chain reaction (PCR) purification kit (Qiagen) and cloned into TA vector using TOPO TA cloning kit (Invitrogen). To humanize the $\mathrm{VH}$ and $\mathrm{VL}$, which originated from the mouse, overlapping PCR was performed to introduce four and three point mutations on VH and VL respectively. The plasmids were then purified using Qiaprep spin miniprep kit (Qiagen) and sent for DNA sequencing at First BASE Laboratories Sdn Bhd (Seri Kembangan, Selangor, Malaysia). Humanized variable region of immunoglobulin light chain (VL) and variable region of immunoglobulin heavy chain $(\mathrm{VH})$ were then double-digested with appropriate restriction enzymes and cloned into pAG4622 and pAH4604 expression vectors (both vectors were kindly provided by Dr. Sherrie Morrison, Department of Microbiology and Molecular Genetics, UCLA, USA) for light and heavy chain, respectively. The recombinant plasmids were named pAG4622-VL and pAH4604-VH.

One day prior to transfection, $1 \times 10^{5} \mathrm{NSO}$ cells (American Type Culture Collection, Manassas, VA, USA) were seeded into each well of a 6-well plate (Corning Inc., Lowell, MA, USA). The cells were grown in growth media consisting of Dulbecco's modified eagle medium (DMEM) (Biochrom AG, Leonorenstr, Berlin, Germany), 1\% glutamax (Invitrogen), 1\% antibiotic/antimycotic (Invitrogen) and 5\% fetal bovine serum (FBS) (Biochrom) and at $37^{\circ} \mathrm{C}, 5 \% \mathrm{CO}_{2}$ and high humidity. The pAG4622-VL and pAH4604-VH were purified in large scale using Qiafilter plasmid maxi kit (Qiagen), linearized by $P v u ~ I$ restriction enzyme (New England Biolabs, Ipswich, MA, USA) and purified again using QIAEX gel extraction kit (Qiagen). Purified linear pAG4622-VL and pAH4604-VH plasmids were each diluted in sterile water to a final concentration of $2 \mu \mathrm{g} / 100 \mu \mathrm{l}$. Transfection complexes were formed by adding 16 $\mu \mathrm{l}$ of FuGENE HD transfection reagent (Roche, GmbH Mannheim, Germany), $100 \mu \mathrm{l}$ of pAG4622-VL (2 $\mu \mathrm{g})$ and $100 \mu \mathrm{l}$ of pAG4604-VH $(2 \mu \mathrm{g})$ in a $1.5 \mathrm{ml}$ centrifuge tube. The mixture was then vortexed vigorously for $5 \mathrm{sec}$ and incubated at room temperature $\left(15-20^{\circ} \mathrm{C}\right)$ for $15 \mathrm{~min}$. Transfection complexes were added to NSO cells drop-wise while the plate was being swirled to ensure even distribution. Cells were then incubated and after $48 \mathrm{hrs}, 3 \mathrm{ml}$ of growth media containing $5 \mathrm{mM}$ of L-histidinol dihydrochloride (Sigma-Aldrich St. Louis, MO, USA), were added every $48 \mathrm{hrs}$ for a duration of 6 days to inhibit the growth of non-transfected cells. Although electroporation and liposome-based reagents are the two most common approaches for transfection, we decided to use FuGENE HD because of its higher efficiency and lower cytotoxicity to mammalian cells (Jacobsen et al. 2009).

\section{Seeding of transfected cells in semi-solid media}

In order to grow clones from individual separate transfected cells, $1 \times 10^{5}$ transfected cells pretreated with L-histidinol dihydrochloride were added to $100 \mathrm{ml}$ of semi-solid growth media comprising of $90 \mathrm{ml}$ semi-solid media for hybridomas/myelomas (cat. no. K8600, Genetix Limited, New Milton, Hamphire, UK), $1 \mathrm{ml}$ antibiotic/antimycotic (Invitrogen), $1 \mathrm{ml}$ glutamax (Invitrogen), $7 \mathrm{ml}$ FBS (Biochrom AG) and 1 $\mathrm{ml}$ of anti-human capture antibody conjugated to fluorescein isothiocyanate (FITC) (cat. no. K8200, Genetix). The mixture was mixed vigorously and $2 \mathrm{ml}$ of the mixture were transferred to each well of equiglass 6 -well plate (Genetix). The plates were then incubated at $37^{\circ} \mathrm{C}, 5 \% \mathrm{CO}_{2}$ with high humidity for 7 days.

\section{Isolation of single high producing clones}

Before each procedure to isolate clones, the Clone Pix FL system (Genetix) was sanitized and calibrated according to the manufacturer's instructions to ensure that the selected colonies were accurately isolated and contamination free. The clones in the semi-solid media were then imaged under white light and also under fluorescence (Lee et al. 2006). Both images were superimposed and the colonies were then sorted according to exterior fluorescent intensity. The individual clones with high 
exterior fluorescent intensity were aspirated with micro-pins controlled by the Clone Pix FL system and dispersed automatically in a 96 well plate containing $160 \mu \mathrm{l}$ of growth media/well. The selected clones could then be transferred for downstream applications. The whole process of sanitization, calibration, imaging of $1 \times 10^{5}$ clones and subsequently selection of high-producers could be completed in $1 \mathrm{hr}$. The clones were then expanded in T75 flasks (Nunc, Thermo Fisher Scientific, Rockford, Illinois, USA).

\section{Quantitative ELISA to determine the antibody productivity of clones}

To evaluate the correlation between the exterior fluorescence intensity and antibody productivity, a quantitative ELISA were performed using supernatant from selected clones with exterior fluorescence intensity of less than 1000 fluorescence units (FU), between 1000-2000 FU, between 2000-3000 FU and all 3 clones with more than 3000 FU. First, immuno 96 micro well solid plates (cat. no. 442404, Nunc) were coated with capture antibodies: anti-human IgG antibody (AHIgG) which is specific to the Fc region of hum-C2 mabs (cat. no. 12136, Sigma-aldrich). AHIgG were diluted 1:2500 in coating buffer ( 0.05 molarity $(\mathrm{M})$ sodium carbonate and $0.05 \mathrm{M}$ of sodium bicarbonate, $\mathrm{pH}$ of 9.6 ). One hundred $\mu$ l of the diluted AHIgG were added to each well. Plates were incubated at $4^{\circ} \mathrm{C}$ for $16 \mathrm{hrs}$ and subsequently washed three times with $200 \mu \mathrm{l}$ of washing buffer (sterile water containing $0.09 \%$ sodium chloride and $0.05 \%$ tween-20) to remove excess antibodies. Plates were blocked by the addition of $200 \mu \mathrm{l}$ of blocking buffer (phosphate buffer containing 3\% bovine serum albumin (BSA) and $0.1 \%$ tween-20) into each well and incubated at $37^{\circ} \mathrm{C}$ for $90 \mathrm{~min}$. Wells were then washed 3 times with washing buffer.

For ELISA, $100 \mu \mathrm{l}$ of sample (undiluted supernatants from each clone with cell densities of $3 \times 10^{6}$ cells $/ \mathrm{ml}$ ) or a standard antibody, immunopure human IgG (cat. no. 31154, Pierce, Thermo Fisher Scientific) with concentrations of $0,6.25,12.5,25,50,100$ and $200 \mathrm{ng} / \mathrm{ml}$ were added in triplicate to designated wells. The plates were incubated at $37^{\circ} \mathrm{C}$ for $90 \mathrm{~min}$. Wells were washed 3 times with washing buffer and $100 \mu \mathrm{l}$ of diluted secondary antibody: anti-human IgG conjugated to peroxidase enzyme (cat. no. A6029, Sigma-Aldrich) were added to each well. The secondary antibody used is specific to the gamma chain ( $\gamma$-chain) of hum-C2 mabs and was diluted to a ratio of 1:2500 in phosphate buffer before use. The mixtures were again incubated at $37^{\circ} \mathrm{C}$ for $60 \mathrm{~min}$. Unbound secondary antibodies were removed by washing and $100 \mu \mathrm{l}$ 2,2'-azino-bis(3-ethylbenzthiazoline-6sulphonic acid (ABTS) substrate solution (cat. no. 11112422001 and 11112597001, Roche) were added. The mixture was incubated at room temperature in the absence of light for 30 min. Finally, the enzyme-substrate reaction was stopped by adding $50 \mu \mathrm{l}$ of 0.5 normality $(\mathrm{N})$ of sulfuric acid and absorbance was measured at 405 nanometer $(\mathrm{nm})$ using a Synergy HT multi-mode microplate reader (BioTek, Winooski, Vermont, USA). A standard curve was plotted and was used to determine the concentration of secreted hum-C2 mabs from the selected clones. Supernatants from the untransfected clones, immunopure Mouse IgG (cat. no. 31202, Roche) and phosphate buffer were also used as negative controls.

\section{RESULTS AND DISCUSSION}

Theoretically, a population of transfected cells should be genetically and phenotypically identical; however, in practice, a significant deviation in growth rate and specific productivity are present (Kim et al. 2001; Barnes et al. 2006). Usually, the population consists of an abundance of non- and lowproducing clones and only a small number of high- producing clones. The growth rates of highproducing clones are relatively lower compared to its low- and non-producing counterparts (Hammill, 2000). This is because in high- producing clones, a large part of their metabolic resources are utilized for antibody production, thus explaining the lower growth rate. Conversely, the non- and low-producing clones are able to utilize more of their metabolic resources for growth. Hence it is vital to select and isolate the high-producing clones before they are overgrown by their non- and low-producing counterparts.

The elimination of non-transfected clones was done by the addition of $5 \mathrm{mM}$ of L-histidinol dihydrochloride, which inhibits the protein synthesis process of non-transfected clones. In theory, increasing the concentration of L-histidinol will eliminate the low-producing clones, however higher concentrations of selective antibiotics were observed to be detrimental to all clones including the highproducers. 
Thus, cloning is required to identify and isolate the high-producing cells. The conventional method of cloning uses liquid media which has many drawbacks (Bailey et al. 2002). Due to the nature of liquid media, it is physically impossible to separate the clones individually, and low- and high-producing cells growing together will eventually lead to the clones to be dominated by low-producing cells. Therefore, semi-solid media has been used to immobilize clones and a high throughput, automated colony picker (Clone Pix FL), use to efficiently isolate monoclonal high-producing clones secreting humanized-C2 monoclonal antibodies. The fluorescence labelling in semi-solid media also allows rapid visualization and discrimination of the rare high secretors from a majority of low producers (Caron et al. 2009).

Seven days after seeding into semi-solid media, discrete colonies derived from transfected cells could be observed. Secreted hum-C2 mabs were retained in the vicinity of their associated colonies because of the semi-solid media's high viscosity. Anti-human-Fc capture antibodies conjugated to FITC added in the semi-solid growth media would bind to secreted hum-C2 mabs to form immunoprecipitates around the colonies. In order to identify high-producing clones, the visible clones were imaged using Clone Pix FL and data from white light and fluorescent images were merged (Figure 1).
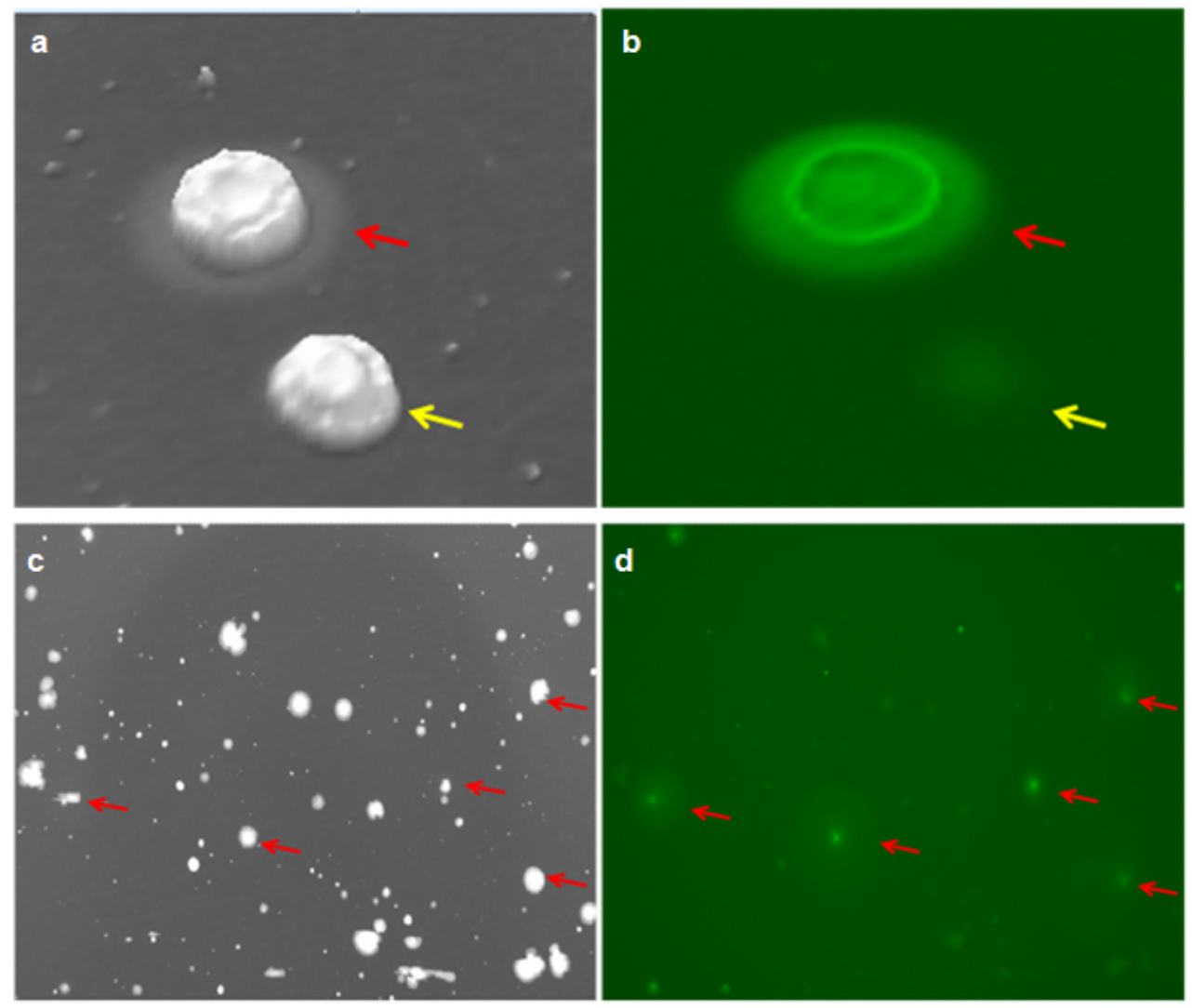

Fig. 1 Screening of colonies under white light and under fluorescence. Cells which are plated in semi-solid media and incubated to form discrete colonies are imaged under white light (Panel a and c) and fluorescence (Panel b and d), respectively. High- and low-producer clones are depicted by the red and yellow arrows, respectively. In monoclonal antibody producing colonies, precipitation is formed around the respective colonies due to the interaction between secreted humanized anti-C2 monoclonal antibodies from the clones and the capture antibody conjugated to FITC. Therefore, the greater the quantity of antibodies secreted, the higher the exterior fluorescent intensity displayed (Panel b and d). In fact, the precipitation around the high producer could be visible even under white light (Panel a).

After screening of all clones, a dot-plot of fluorescence unit (exterior fluorescent intensity) against area of colonies was generated (Figure 2). From the plot, it is obvious that the intensity of fluorescence was inversely related to the area of the colonies and that the majority of the colonies had intensities of less than 1000 fluorescence units (FU) which served as the threshold for our purposes. From a total of $1 \mathrm{x}$ 
$10^{5}$ clones possible, only $271(\sim 0.271 \%)$ clones were above the threshold value of 1000 (FU). Furthermore, of the 271 significantly producing clones, $217(\sim 0.217 \%), 51(\sim 0.051 \%)$ and only 3 $(0.003 \%)$ clones had readings of between 1000-2000 FU, 2000-3000 FU and 3000-4000 FU, respectively. The extremely low percentage of high producers, clearly shows the rationale of using a high throughput selection method to screen large numbers of clones. The fact that clones with low fluorescence intensity occupy larger areas, reinforces the fact that non- or low-producing clones had greater growth rates and so it is important to separate them from the high-producers at as earlier a point as possible to prevent the latter from being outcompeted.

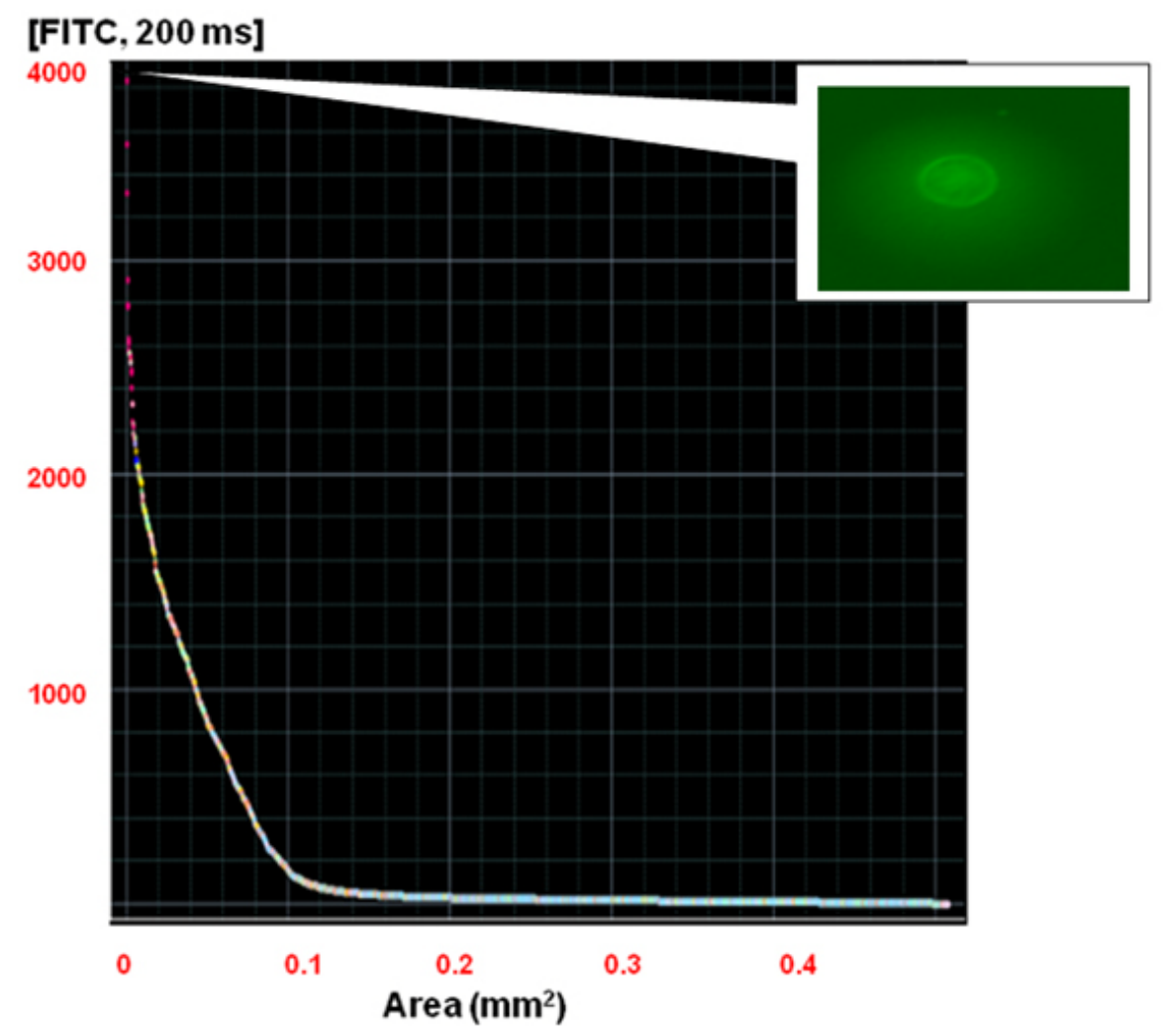

Fig. 2 Dot-plot analysis of fluorescence unit (FITC, $200 \mathrm{~ms}$ ) against colony size (Area, $\mathbf{m m}^{2}$ ). After colonies are imaged, a dot-plot is the generated for all the colonies. Each coloured dot represents a particular colony, e.g. the dot with highest exterior fluorescent intensity, $3840 \mathrm{FU}$ can be identified as a single discrete colony as shown above. From a total of $1 \times 10^{5}$ clones, only 217,51 and 3 clones were between 1000-2000 FU, 2000-3000 FU and more than $3000 \mathrm{FU}$, respectively. Almost $99.73 \%$ of the clones were low-producers with less than $1000 \mathrm{FU}$. Another significant trend observed is the decreasing colony size with the increase in fluorescent intensity. In fact all colonies with fluorescence of more than $1000 \mathrm{FU}$ were less than $0.04 \mathrm{~mm}^{2}$ in area. Thus, an incubation period of 7-10 days is optimum for high viability of isolated high producers.

The correlation between fluorescence intensity and antibody productivity was evaluated in selected clones using ELISA method to measure the levels of antibodies in the supernatants of cells at a concentration of $3 \times 10^{6} \mathrm{cells} / \mathrm{ml}$. Clones with less than $1000 \mathrm{FU}$ had low productivity of less than 1.0 $\mu \mathrm{g} / \mathrm{ml}$. In clones with 1000-2000 FU, 2000-3000 FU and greater than $3000 \mathrm{FU}$, there appeared to be no difference in antibody productivity with the increase in fluorescence intensity (Table 1). Theoretically, at equivalent cell densities, clones with higher the exterior fluorescence intensities should have higher concentration of antibodies being secreted. Furthermore, it has been reported that secreted recombinant protein levels correlated well with their fluorescence intensities (Caron et al. 2009). However, our results show that at equivalent cell densities of $3 \times 10^{6} \mathrm{cells} / \mathrm{ml}$, the exterior fluorescence intensities and antibody productivity or our humanized cells does not correlate well for clones above $1000 \mathrm{FU}$. Some clones having low exterior fluorescence intensity such as clone B4 with $1749 \mathrm{FU}$ has a higher antibody concentration of $11.0 \mu \mathrm{g} / \mathrm{ml}$ compared to $8.6 \mu \mathrm{g} / \mathrm{ml}$ secreted by clone D3 which has the highest fluorescence intensity of 3840 FU. It was also noticed that clone D2 with 
fluorescence intensity of $3545 \mathrm{FU}$, secreted only $1.4 \mu \mathrm{g} / \mathrm{ml}$. This could be due to instability of the clone which accounts for the subsequent loss of antibody productivity upon further culturing.

Thus it can be concluded that in general, for our clones secreting hum-C2 mAbs, clones with readings of greater than $1000 \mathrm{FU}$ would be considered high producers. However, clones with the highest FU readings do not necessarily mean that they would the highest producers, and clones chosen for further development will need to be evaluated further to confirm their productivity. Of all the $1 \times 10^{5}$ transfected cells seeded, $217(0.217 \%)$ clones had fluorescence readings of greater than $1000 \mathrm{FU}$ and $3(0.003 \%)$ had FU of greater than 3000 . Thus it is possible to identify rare high producing cells at a rate of as low as $0.003 \%$ of the whole population with a great degree of confidence of monoclonality within 7 days of cloning for further evaluation, which is impossible with other commonly used methods.

Although LDC method is comparably high-throughput in comparison with other traditional selection methods, only a few hundred clones can realistically be characterized, thus increasing the chance of missing out on high-producers due to the relatively low number of cells screened. This method may also take a significantly longer time (1-2 months) to screen for significantly producing cells. A significant problem of LDC method and other conventional methods is that it makes assumptions that highproducing clones obtained are monoclonal, i.e. derived from a single cell. Statistical analysis of the LDC method shows that after repeated rounds, monoclonality still is not guaranteed (Underwood and Bean, 1988). Monoclonality is important because in a hetrogenous population non-producing will overgrow producing cells and presents a barrier to the enhancement of product yields A growth advantage of as little as $9 \%$ is sufficient for overgrowth by low- or non-producers to occur after 25 passages. Thus, the requirement for the production of monoclonal antibodies in industrial cell culture is that the producing cell line is monoclonal (Barnes et al. 2006).

Table 1. Comparison of exterior fluorescence intensity (FU) and antibody productivity ( $\mu \mathrm{g} / \mathrm{ml}$ ) of clones selected by Clone Pix FL system. In general, clones above 1000 FU secretes humanized anti-C2 antibody with at least five times superiority compared to that of clones below 1000 FU. However, no correlation was observed between exterior fluorescence intensity and antibody productivity for clones with more than $1000 \mathrm{FU}$.

\begin{tabular}{|c|c|c|}
\hline Clones & Exterior fluorescence intensity (FU) & Antibody productivity $(\mu \mathrm{g} / \mathrm{ml})$ \\
\hline \multicolumn{3}{|c|}{$<1000$} \\
\hline Clone A1 & 273 & 0.6 \\
\hline Clone A2 & 508 & 0.8 \\
\hline Clone A3 & 573 & 0.6 \\
\hline Clone A4 & 870 & 0.4 \\
\hline Clone A5 & 937 & 0.6 \\
\hline \multicolumn{3}{|c|}{$1000-2000$} \\
\hline Clone B1 & 1107 & 8.3 \\
\hline Clone B2 & 1511 & 6.0 \\
\hline Clone B3 & 1648 & 11.4 \\
\hline Clone B4 & 1749 & 11.0 \\
\hline Clone B5 & 1968 & 7.4 \\
\hline \multicolumn{3}{|c|}{$2000-3000$} \\
\hline Clone C1 & 2173 & 11.2 \\
\hline Clone C2 & 2479 & 8.8 \\
\hline Clone C3 & 2786 & 11.0 \\
\hline Clone C4 & 2910 & 7.2 \\
\hline Clone C5 & 2935 & 5.0 \\
\hline \multicolumn{3}{|c|}{$>3000$} \\
\hline Clone D1 & 3318 & 8.7 \\
\hline Clone D2 & 3545 & 1.4 \\
\hline Clone D3 & 3840 & 8.6 \\
\hline
\end{tabular}


With liquid media, it is impossible to be entirely certain that the cell line generated is derived from a single cell, and cell lines can only be said to have a probability of being monoclonal (Staszewski, 1990). However using Clone Pix FL system (Mann, 2007), growing colonies in semi-solid medium allows the clonal progeny of a single cell to stay together. The colonies are therefore monoclonal from the start. In addition, to isolate the high-producing monoclonal clones for downstream applications, an automated colony picker, Clone Pix FL system was used. Using pre-programmed software and micropins, the desired clones were selected without contamination from neighbouring clones. Hence, the clones which were initially monoclonal, remained monoclonal during incubation and even after isolation.

Nevertheless, there are a few other issues of using Clone Pix FL system that need to be addressed. First, although by this method for our hum-C2 mAbs transfected cells, we can separate high producing colonies from their low producing counterparts, it not advisable to seed more than $1000 \mathrm{cells} / \mathrm{ml}$ in semi-solid growth media. This is because the use of more than 1000 cells $/ \mathrm{ml}$ will increase the risk of overlapping of precipitation of secreted proteins between two or more colonies, hence giving a false positive high fluorescent reading. Second, it is also vital to incubate the clones in semi-solid media for at least 7 days but not more the 10 days prior to picking. This is to ensure that the high-producing clones will have reached a viable size and can be detected. From Figure 2, most of high producing clones have small areas compared to low-producers: therefore isolation of clones before 7 days might lead to low viability after isolation. However, incubation of more than 10 days is discouraged as this can lead to overgrowth of low-producing clones and subsequently the loss of producing clones. Thus the optimum cell concentration and duration of incubation should be between $800-1000$ cells $/ \mathrm{ml}$ and $7-10$ days depending on cell type.

In summary, the use of semi-solid growth media and the high throughput ability of Clone Pix FL system enable the screening a large number of clones and increase the probability of finding high-producer clones which are extremely rare. These high- producing clones can be isolated in just 7 days are also monoclonal which is important for large scale production of monoclonal antibodies. In addition, the rapid and fully automated nature of Clone Pix FL method is also more time- and labour-efficient and has a lower risk of cross clone contamination. However, because there is no linear proportionality between exterior fluorescence intensity obtained by Clone Pix FL system to antibody productivity for clones above $1000 \mathrm{FU}$, downstream analysis is vital to determine the 'actual' and stable high producer clones.

Financial support: This research was supported by Ministry of Science, Technology and Innovation, Malaysia.

\section{REFERENCES}

AKSELBAND, Y.; MOEN, P.T. Jr. and MCGRATH, P. (2003). Isolation of rare isotype switch variants in hybridoma cell lines using an agarose gel microdrop-based protein secretion assay. ASSAY and Drug Development Technologies, vol. 1, no. 5, p. 619-626. [CrossRef]

BAILEY, C.G.; TAIT, S.A. and SUNSTROM, N.-A. (2002). High-throughput clonal selection of recombinant CHO cells using a dominant selectable and amplifiable metallothionein-GFP fusion protein. Biotechnology and Bioengineering, vol. 80, no. 6, p. 670-676. [CrossRef]

BARNES, L.M.; BENTLEY, C.M. and DICKSON, A.J. (2001). Characterization of the stability of recombinant protein production in the GS-NS0 expression system. Biotechnology and Bioengineering, vol. 73, no. 4, p. 261-270. [CrossRef]

BARNES, L.M.; MOY, N. and DICKSON, A.J. (2006). Phenotypic variation during cloning procedures: Analysis of the growth behavior of clonal cell lines. Biotechnology and Bioengineering, vol. 94, no. 3, p. 530-537. [CrossRef]

BORTH, N.; ZEYDA, M. and KATINGER, H. (2000). Efficient selection of high-producing subclones during gene amplification of recombinant Chinese hamster ovary cells by flow cytometry and cell sorting. Biotechnology and Bioengineering, vol. 71, no. 4, p. 266-273. [CrossRef]

BROWNE, S.M. and AL-RUBEAI, M. (2007). Selection methods for high-producing mammalian cell lines. Trends in Biotechnology, vol. 25, no. 9, p. 425-432. [CrossRef]

BUTLER, M. (2005). Animal cell cultures: Recent achievements and perspectives in the production of biopharmaceuticals. Applied Microbiology and Biotechnology, vol. 68, no. 3, p. 283-291. [CrossRef]

CARON, A.W.; NICOLAS, C.; GAILLET, B.; BA, I.; PINARD, M.; GARNIER, A.; MASSIE, B. and GILBERT, R. (2009). Fluorescent labeling in semi-solid medium for selection of mammalian cells secreting high-levels of recombinant proteins. BMC Biotechnology, vol. 9, no. 42. [CrossRef] 
CARROLL, S. and AL-RUBEAI, M. (2004). The selection of high-producing cell lines using flow cytometry and cell sorting. Expert Opinion on Biological Therapy, vol. 4, no. 11, p. 1821-1829. [CrossRef]

CARROLL, S. and AL-RUBEAI, M. (2005). ACSD labelling and magnetic cell separation: A rapid method of separating antibody secreting cells from non-secreting cells. Journal of Immunological Methods, vol. 296, no. 1-2, p. 171-178. [CrossRef]

DEMARIA, C.T.; CAIRNS, V.; SCHWARZ, C.; ZHANG, J.; GUERIN, M.; ZUENA, E.; ESTES, S. and KAREY, K.P. (2007). Accelerated clone selection for recombinant CHO cells using a FACS-based high-throughput screen. Biotechnology Progress, vol. 23, no. 2, p. 465-472. [CrossRef]

FRYKMAN, S. and SRIENC, F. (1988). Quantitating secretion rates of individual cells: Design of secretion assays. Biotechnology and Bioengineering, vol. 59, no. 2, p. 214-226. [CrossRef]

HAMMILL, L.; WELLES, J. and CARSON, G. (2000). The gel microdrop secretion assay: Identification of a low productivity subpopulation arising during the production of human antibody in $\mathrm{CHO}$ cells. Cytotechnology, vol. 34, no. 1-2, p. 27-37. [CrossRef]

HANANIA, E.G.; FIECK, A.; STEVENS, J.; BODZIN, L.J.; PALSSON, B.O. and KOLLER, M.R. (2005). Automated in situ measurement of cell-specific antibody secretion and laser-mediated purification for rapid cloning of highly-secreting producers. Biotechnology and Bioengineering, vol. 91, no. 7, p. 872-876. [CrossRef]

IZNAGA-ESCOBAR, N.; RAMOS-SUZARTE, M.; MORALES-MORALES, A.; TORRES-AROCHA, L.; RODRIGUEZMESA, N. and PEREZ-RODRIGUEZ, R. (2004). 99mTc-labeled murine ior C5 monoclonal antibody in colorectal carcinoma patients: Pharmacokinetics, biodistribution, absorbed radiation doses to normal organs and tissues and tumor localization. Methods and Findings in Experimental and Clinical Pharmacology, vol. 26, no. 9, p. 687-696. [CrossRef]

JACOBSEN, L.B.; CALVIN, S.A. and LOBENHOFER, E.D. (2009). Transcriptional effects of transfection: The potential for misinterpretation of gene expression data generated from transiently transfected cells. Biotechniques, vol. 47, no. 1, p. 617-624. [CrossRef]

KACMAR, J. and SRIENC, F. (2005). Dynamics of single cell property distributions in Chinese hamster ovary cell cultures monitored and controlled with automated flow cytometry. Journal of Biotechnology, vol. 120, no. 4, p. 410-420. [CrossRef]

KIM, N.S.; BYUN, T.H. and LEE, G.M. (2001). Key determinants in the occurrence of clonal variation in humanized antibody expression of $\mathrm{CHO}$ cells during dihydrofolate reductase mediated gene amplification. Biotechnology Progress, vol. 17, no. 1, p. 69-75. [CrossRef]

KOLLER, M.R.; HANANIA, E.G.; STEVENS, J.; EISFELD, T.M.; SASAKI, G.C.; FIECK, A. and PALSSON, B.O. (2004). High-throughput laser-mediated in situ cell purification with high purity and yield. Cytometry Part $A$, vol. 61A, no. 2, p. 153-161. [CrossRef]

LEE, C.; LY, C.; SAUERWALD, T.; KELLY, T. and MOORE, G. (2006). High-throughput screening of cell lines expressing monoclonal antibodies. Bioprocess International, vol. 4, sup. 3, p. 32-35.

MANN, C.J. (2007). Rapid isolation of antigen-specific clones from hybridoma fusions. Nature Methods, vol. 4, no. 4.

MATEO, C.; LOMBARDERO, J.; MORENO, E.; MORALES, A.; BOMBINO, G.; COLOMA, J.; WIMS, L.; MORRISON, S.L. and PEREZ, R. (2000). Removal of amphipathic epitopes from genetically engineered antibodies: Production of modified immunoglobulins with reduced immunogenicity. Hybridoma, vol. 19, no. 6, p. 463-471. [CrossRef]

MENG, G.Y.; LIANG, J.; WONG, W.-L. and CHISHOLM, V. (2000). Green fluorescent protein as a second selectable marker for selection of high producing clones from transfected $\mathrm{CHO}$ cells. Gene, vol. 242, no. 1-2, p. 201-207. [CrossRef]

ROQUE-NAVARRO, L.; MATEO, C.; LOMBARDERO, J.; MUSTELIER, G.; FERNANDEZ, A.; SOSA, K.; MORRISON, S.L. and PEREZ, R. (2003). Humanization of predicted T-cell epitopes reduces the immunogenicity of chimeric antibodies: New evidence supporting a simple method. Hybridoma and hybridomics, vol. 22, no. 4, p. 245-257. [CrossRef]

STASZEWSKI, R. (1990). Murphy's law of limiting dilution cloning. Statistics in Medicine, vol. 9, no. 4, p. 457-461. [CrossRef]

UNDERWOOD, A.P. and BEAN, P.A. (1988). Hazards of the limiting-dilution method of cloning hybridomas. Journal of Immunological Methods, vol. 107, no. 1, p. 119-128. [CrossRef]

WURM, F.M. (2004). Production of recombinant protein therapeutics in cultivated mammalian cells. Nature Biotechnology, vol. 22, no. 11, p. 1393-1398. [CrossRef]

YAZAKI, P.J.; SHERMAN, M.A.; SHIVELY, J.E.; IKLE, D.; WILLIAMS, L.E.; WONG, J.Y.C.; COLCHER, D.; WU, A.M. and RAUBITSCHEK, A.A. (2004). Humanization of the anti-CEA T8.66 antibody based on crystal structure data. Protein Engineering Design and Selection, vol. 17, no. 5, p. 481-489. [CrossRef]

YOSHIKAWA, T.; NAKANISHI, F.; OGURA, Y.; OI, D.; OMASA, T.; KATAKURA, Y.; KISHIMOTO, M. and SUGA, K.-I. (2001). Flow cytometry: An improved method for the selection of highly productive gene-amplified $\mathrm{CHO}$ cells using flow cytometry. Biotechnology and Bioengineering, vol. 74, no. 5, p. 435-442. [CrossRef] 


\section{How to cite this article:}

DHARSHANAN, S.; CHONG, H.; HUNG, C.S.; ZAMROD, Z. and KAMAL, N. (2011). Rapid automated selection of mammalian cell line secreting high level of humanized monoclonal antibody using Clone Pix FL system and the correlation between exterior median intensity and antibody productivity. Electronic Journal of Biotechnology, vol. 14, no. 2. http://dx.doi.org/10.2225/vol14-issue2-fulltext-7 